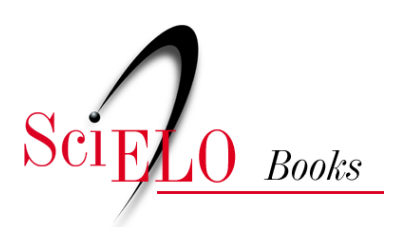

\title{
18. Edison de Jesús Fernández
}

\author{
César Augusto Tapias Hernández
}

\section{SciELO Books / SciELO Livros / SciELO Libros}

TAPIAS HERNÁNDEZ, C.A. Edison de Jesús Fernández. In: Historias de familia: Etnografía delirante sobre el amor, la violencia y las drogas [online]. Bogotá: Editorial Universidad del Rosario, 2014, pp. 75-80. Textos de ciencias humanas collection. ISBN: 978-958-738-543-4. https://doi.org/10.7476/9789587385434.0019.

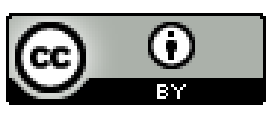

All the contents of this work, except where otherwise noted, is licensed under a Creative Commons Attribution 4.0 International license.

Todo o conteúdo deste trabalho, exceto quando houver ressalva, é publicado sob a licença Creative Commons Atribição 4.0.

Todo el contenido de esta obra, excepto donde se indique lo contrario, está bajo licencia de la licencia $\underline{\text { Creative }}$ Commons Reconocimento 4.0 . 


\title{
18. Edison de Jesús Fernández
}

\author{
¿Vienes de trabajar? \\ Si, ¿por qué? \\ ¿Ese es el ejemplo que le das a tu hermano mayor? ¡Qué \\ vergüenza! Tu hermano jamás ha trabajado, siempre ha hecho \\ lo que ha querido. Eres un degenerado. \\ Pier Paolo Pasolini, Accattone
}

Esta iba a ser la historia del tío Gildardo; pero también será sobre un hijo suyo y por cuya existencia, al descubrirla tan tarde, me sorprendí. Un primo que nunca conocí...

Yo sí sabía que mi tío Gildardo alguna vez estuvo casado con una mujer de nombre Dolores, que dizque se había casado prendidito — casi borracho-, lo cual fue un escándalo en El Pedregal; que de esa vuelta quedaban dos peladas todas linditas ellas a las que solo se les veía en la familia una o dos veces al año. Que separado ya algunos años después, se fue pa’ Venezuela a trabajar. ¡Ah!, y tengo muy presente, además, que buena parte de la vida ha sido mesero, y que es uno de los hombres que más quiere a mi mamá.

-Tío, vine para que me contés un chisme.

-Qué será mijo...

- ¿Cómo así que vos tuviste un hijo?

Y el tío Gildardo, sin dudarlo, dice que sí. Y antes que la respuesta, preferiría más bien saber qué pensó "Gilda" frente a esa pregunta... Lo que al principio me pareció una evasiva, fue ver al tío salir para su habitación dejándome ahí solo, pero regresó pronto con un par de fotos suyas. Primero, una donde Gildardo no parece que fuera él: acompañado de Edison y Adriana, dos de los tres hijos que tuvo con Dolores. En esa foto, Gildardo posa con todas las pretensiones de ser eterno: él con su cabello largo. La otra es una foto de una niña morenita, de cuerpito entero, que apenas 
comenzaba a caminar: su hija Mary Luz. Ambos retratos, copias muy regulares de las fotografías originales, se mostraban en exceso contrastadas al blancos y negros estallados-detentores del tiempo, pretensión de toda fotografía, retratos de sensaciones ya perdidas (de vista) u olvidadas (de memoria)...

En la sala de su casa, con la mirada lanzada a la calle por el ventanal grande de la sala, sentado en el mueble, de camiseta blanca por fuera, pantalón y chanclas, y con las medias puestas, mi tío Gilda se encamina a recordar:

- Lo mataron cuando tenía dieciocho o diecinueve años.

-Y eso ¿por qué, tío?

- Porque era malo y mantenía con esos muchachos malos de El Pedregal.

-Y ¿cómo era ser malo en esos días?

—Un ladrón... un marihuanero ahí.

Que en un tiempo no lo dejaban ni arrimar a la casa siquiera. El Edison le robaba hasta a los tíos... Y la mamá Dolores, que había sido una alcahueta de toda la vida, según cuenta el tío, lo dejaba entrar por el solar cuando el abuelito, don Pedro, y los tíos estuvieran durmiendo... Se la pasó callejeando y entrando por el patio hasta el día en que perdió...

- Por ahí más arriba de la escuela especial, por los lados de la cañada, estaban en un baile él, unos amigos... y de pronto lo llamaron unas muchachas. Él como que salió a conversar con ellas y fue en ese momento cuando lo mataron. Era de madrugada, y a mí me llamaron como a las siete... Me avisaron apenas a esa hora que lo habían matado... Eso fue como en el 85, a los dí́tas de muerta mi amá...

Cómo era Edison es, quizás, la incógnita del momento, por lo menos para mí. Y me sorprendía sobremanera, porque no creí posible siquiera pensar un tipo así en la familia de mamá. Aunque es comprensible, después de todo, la ciudad en sus ansias de crecer... los barrios populares... el rebusque... la esquina oscura, un tango y un café... Todos los Fernández vinieron a la ciudad ya creciditos, mi mamá era la niña, entonces sería la siguiente generación la encargada de demoler las aceras... padecerlas... El tío era un tipo joven para cuando Edison, callejeando, también lo era... Y me atreví entonces a preguntarle a "Gilda”, alabándolo de paso un poco, que si acaso su hijo no se habría parecido a él. Y muy seguro, rápido y confiado "Gilda" contesta decididamente que sí.

— ¡Yo tenía el pelo largo!

Lo confesó en cuanto pasó a contarme algo de Miriam Lotero, la mujer con quien vive como desde 1984 (y con quien tiene una niña bonita, Karina). Asombrado por lo del cabello largo, le pregunto que si es que fue roquero o algo así, camaján 
o pilluelo, y que si había fumado marihuana alguna vez... Y él a todo diciendo de una que no. NO...

NO... NO...

La pinta del tío cuando era joven era una de mucho estilo: patilla larga un toque, y en efecto de cabello largo pero bien cortadito... Las fotos por la tradicional calle Junín, en el centro de la ciudad, lo muestran usando camisas de colores en estampados bien sollados, de mangas largas, correas en cuero gruesas, gruesas como las chapas; chaquetas elegantes y un porte de bacán... hasta creo que se ponía sombreros... (Pero no veo pruebas).

-Yo vestía bien. Usaba un buen reloj, mis anillos... Me gustaba vestir bien... a lo mejor será por eso que...

-Será... que qué...

-Que ahora no me va tan bien...

- Pensás que fuiste vanidoso o qué.

-iNo!

Gildardo de Jesús Fernández Quiroz se casó el 25 de septiembre de 1965, recién cumplido los veintiún y Dolores apenas con diecinueve. Sin embargo, la cosa no andaba bien y pa'l año 1971 ya estaban separados. Vivían con los suegros y el tío con ganas de casa pa' ellos solos... Y, en efecto, de puro amor un día la consiguió; pero Dolores dizque prefería quedarse con sus papás. “Gilda” no aguantó y se regresó para donde los suyos: papito Gabriel y mamita Laura. Y, por si fuera poco, una orden de la inspección de El Pedregal le impedía volver a la casa (donde los padres de Dolores que eran donde vivían). Solo hasta cuando las muchachas estuvieron grandes pudo estar junto a ellas. Antes, según palabras suyas, la Dolores les decía a ellas que no tenían papá...

A pesar de ello, "Gilda" entregó ante el altar a sus dos hijas cuando a bien tuvieron casarse. Fue leal a su condición de padre, aunque desde el exilio... Y regocijado en el momento del recuerdo, deja ver el tío muestras de que en su momento le rogó a Dolores para que se fueran juntos: la familia. Y ella como que nada de nada. Estaba decidida a quedarse en casa con sus padres (salvo un par de veces en que Edison prometió cambiar y se fueron los cuatro: Dolores, Edison y las muchachas, a una casa solo para ellos: la familia. Pero Edison volvía y la cagaba y de nuevo adonde don Pedro). Eso de rogar por amor es algo que el tío no confiesa propiamente; pero seguro seguía enamorado. Lo casual de todo esto es que era la misma Miriam la que le llevaba razones a la Dolores de parte del Gildardo... y regresaba la Miriam que cuando señorita era una morena delgadita y bien bonita, diciéndole al tío que mejor se buscara otra 
mujer... Que Dolores no paraba bola, y qué casualidad que la otra mujer resultaría siendo ella misma... Qué casualidad... Vaya, vaya... El tío Gildardo y su hija Ana Karina sonríen cuando digo que a lo mejor Miriam tenía sus intenciones cuando daba la razón esa:

—No, negro, mejor búsquese otra mujer que sí lo quiera... Y resultó con dos: Miriam y otra pinta: Ana Karina (la niña bonita).

Lo del Edison, Dolores y Miriam; las peleas del tío cuando borracho por la avenida principal del barrio... Los abuelos y esa casa de dos patios... Puras sensaciones de olores que vuelven con solo pensar y decir un nombre: El Pedregal (un pedregal fue tu amor, cantaba Justo Bentancurt...).

-El Pedregal es mucho mucho mejor de noche.

- Me lo encontraba por ahí con sus amigos y de una me salía al paso y me pedía plata: "Cucho, cucho... — me decía cucho-”. Una vez me iban a atracar. Ya me había quitado el reloj y una plata. Como a eso de la 1:30 de la mañana me cogieron unos manes ahí junto a "El Palmar”. De pronto apareció el niño y les fue diciendo a los que me agarraron: "Hey, hey, pilas. Pilas, pues, que ese es mi cucho. Me le devuelven todo ya”.

-Y un pillo en esos días, ¿cómo se movía? ¿Tenía su moto o qué? — pregunto.

-No. El niño nunca tuvo de eso, como que andaba era con un amigo que sí tenía.

— ¿Verdad que estuvo en silla de ruedas por los días de velorio de la abuela Laura?

—Nooooo, eso es falso. A él... el día que le dieron, le dieron y se murió.

Según cuentan, un tiempo se estuvo en la ciudad de Cali y por allá con otra gente atracó almacenes Ley y quién sabe cuántos lugares más. Fue un tipo de golpes grandes y bajos que también recibió sus palmadas en la cara y en la nalga, aunque en vano quizás. Un día le robó un billete a papito Gabriel, era la segunda vez... El papito le había puesto la plata como cascarita y el pelao, en efecto, se resbaló: en tanto el viejo se pilló la ausencia del dinero, correa en mano se le fue encima... Lo echó para donde Dolores.

Tenía que pasar la avenida principal del barrio, luego la calle del pecao, y más allá por el bulevar donde todavía hoy se pasan la vida fumando marihuana. Esta calle lo transformó, anduvo en esta morada de pillos y vagos... Pasó por estos lugares y por encima no sé de quién más.... El pobre Edison llevó su pela... ¿Cómo imaginar a don Gabriel Fernández pegándole a un nieto suyo? Tampoco imagino al primo 
Edison... Por aquellos días, copiloto a lo mejor de una moto 100 roja o amarilla, dándose unos roces por el barrio, mostrándose...

Y ¿si no hubiera muerto...? Seguro seguiría diciéndole a mi tío "cucho”. Y como sé que el primo no habría dejado de ser el primo, así como mi tío H que no ha dejado de ser $\mathrm{H}$, el mismo Edison, como un personaje de un poema de Helí Ramírez seguiría cogiéndole el paso a la angustia que impele a la vida...

Con unos 33 o 34 años, según cálculos improvisados... tal vez estaría fumando yerba conmigo mientras me relata sus andanzas para este libro.

Pero de los recuerdos que quedan de verdad en mi cabeza, tengo al tío Gildardo levantándose tarde, en su bata de baño gris, cepillándose los dientes en el patio de atrás... Su habitación era la habitación de atrás... Para muchos eso de un divorcio o una separación sería un fracaso, yo pienso que es como un nuevo chance, opción de nuevas cosas... De pronto me sorprendo al ver cómo al final de esta charla Gildardo telefonea a Dolores, su exmujer:

— ¡Hola, querida! ¿Cómo estás?

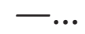

—Oís, es que un sobrino mío que estudió sociología o algo así está haciendo una reconstrucción de las historias de la familia...

-...

— ¿Hace cuánto fue que nos mataron al niño?

-...

- ¿Y vos no tenés una foto de él por ahí?

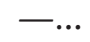

$\infty \infty \infty$

En plena investigación, truncada por la violencia política, el profesor Hernán Henao halla un documento de la Corporación Región, donde se señala que las causas de la violencia "de mil cabezas" que cunde en Medellín se resumen (para los años noventa) así:

La crisis de la institucionalidad política y el Estado. La ausencia de una ética social. Un ambiente social de tolerancia con el delito y la corrupción. La impunidad generalizada como consecuencia de la ineficiencia de la administración de justicia. La corrupción de los organismos de seguridad del Estado. La situación socioeconómica. La influencia del narcotráfico. La crisis de los modelos culturales tradicionales y ausencia de una cultura urbana sólida. 
Este último enunciado es el que anima las inquietudes del profesor Henao cuando trata de comprender al monstruo en que la ciudad se convirtió, al mismo tiempo que plantea el ánimo descriptivo de esta etnografía experimental: ¿cómo vivió mi familia ese aumento de la migración a la ciudad de Medellín de trescientos mil habitantes en 1951 a casi dos millones en los años noventa?

En un periodo de 30 años — dice el profesor - no están en capacidad de asimilar los cambios culturales que se producen en las generaciones nuevas, desarraigadas en su propio entorno familiar y vecinal, pero además ausentes de viviendas pueblerinas campesinas que les hubiesen permitido configurar su personalidad social por el camino de la comparación de modos de vida. (Henao, 1995, p. 9)

Recuperar valores perdidos frente a construir nuevos valores pareciera ser la primera tarea en la ciudad del fin de siglo. Volver a dilucidar el trasfondo de la sociedad rural, decimonónica, que permitió elaborar el mito de la antioqueñidad: esa es la realidad de mi familia, resultante de medio siglo de grandes transformaciones, el hecho grueso que se pone sobre este tapete etnográfico. Veamos, por ejemplo, cómo la familia de mi mamá ha transitado desde Titiribí a Nueva Jersey, o bien buscando alternativas económicas o huyendo de la guerra. 